\title{
Itinerários de escolarização e mediações subjacentes: a experiência de discentes beneficiários do Prouni
}

Andrea Bayerl Mongim ${ }^{a}$

\section{Resumo}

Neste artigo analiso itinerários sociais de estudantes oriundos de famílias consideradas de classes populares e beneficiários do Prouni. Discuto o processo de constituição de significados e de incorporação prática de princípios que concorreram para construção e objetivação do projeto de aquisição do título universitário. Tal projeto é construído de forma não naturalizada, efetivando-se pela interação com agentes mediadores, posicionados em quadros institucionais que ultrapassam os limites da família nuclear. A mediação formal-legal dos agentes do Prouni apresenta-se como fundamental. Todavia, o processo de permanência e conclusão do curso é marcado por muitos dilemas, tanto nas formas de relacionamento com a alteridade como nas de ordem financeira. A conclusão do curso superior representa a possibilidade de exercer profissão melhor remunerada e valorizada, e de incluir-se em grupo de maior prestígio e status.

Palavras-chave: Prouni. Título universitário. Mediação social.

\section{Introdução}

Neste artigo, tomo como unidade de análise itinerários sociais de estudantes que, oriundos de famílias consideradas de classes populares, ingressaram em Instituição de Ensino Superior privada, na condição de beneficiários do Programa Universidade Para Todos - Prouni ${ }^{1}$. O estudo incide sobre contexto em que o acesso ao Ensino Superior se constitui como problemática política, expressa, sobretudo, por lutas em prol da diminuição do quadro de desigualdades socioeconômicas da

a Universidade Federal do Espírito Santo - UFES. Vitória, Espírito Santo, Brasil.

O Programa Universidade para Todos (Prouni) foi instituído, em 2004, pelo Governo Federal, através de Decreto-lei, destinando bolsas integrais e parciais (50\%) a estudantes considerados de baixa renda, em Instituições de Ensino Superior privadas. 
população, merecendo destaque o implemento de políticas de bolsas de estudo em Instituições de Ensino Superior (IES) privadas e de reserva de vagas em IES públicas. Por efeito de tais lutas, nas últimas três décadas, sobretudo a partir dos anos 1990, o campo do Ensino Superior vem se caracterizando por transformações que, no plano mais genérico, reafirmam-se pela inclusão de estudantes oriundos das consideradas classes populares. O aumento da demanda por esse nível de ensino é claramente percebido através das diferentes estratégias construídas para ampliar o acesso às universidades. Conforme demonstra Souza (2003), a partir dos anos 1990, expandiram-se por todo o país movimentos sociais com este objetivo, especialmente os cursos pré-vestibulares alternativos, gratuitos ou sem fins lucrativos. Em paralelo e referenciadas pelo debate internacional do movimento negro, que proclama o implemento de ações afirmativas ${ }^{2}$ para a redução das desigualdades de oportunidades, essas organizações, no Brasil, têm atuado na defesa de políticas que garantam o ingresso no Ensino Superior, especialmente através da reserva de cotas para negros, oferecidas nas universidades públicas.

O designado processo de inclusão no Ensino Superior, reivindicado por representantes de diferentes movimentos sociais e levado à frente por implementação de recentes políticas de ação afirmativa, vem assumindo contornos polêmicos e instituindo um acalorado debate, tanto no espaço público como no campo acadêmico, como demonstram, entre outros, Heringer e Ferreira (2009).

No que mais interessa para efeito de elaboração deste artigo, enfatizo o quanto o debate público sobre o Prouni vem ganhando espaço nas pautas de análises acadêmicas.

Apesar disto, a maior parte dos autores que busca analisar programas de reserva de cotas nas universidades, ou que analisa o Prouni como uma extensão do projeto de privatização do Ensino Superior, o faz com base em pesquisas de caráter documental e bibliográfico. Os trabalhos produzidos por Almeida (2006) e Carvalho (2006) são representativos desta perspectiva.

A análise relativa às concepções e práticas dos atores envolvidos diretamente no processo, na condição de beneficiários desses programas, acaba por ser assim secundarizada em tais estudos.

Por esta via, tomo como proposta neste texto analisar os itinerários sociais de estudantes universitários considerados de classes populares e beneficiários do

\footnotetext{
Por políticas de ação afirmativa entende-se "medidas especiais e temporárias, tomadas pelo Estado e/ou pela iniciativa privada, espontânea ou compulsoriamente, com o objetivo de eliminar desigualdades historicamente acumuladas, [...] de garantir a igualdade de oportunidade e tratamento, bem como compensar perdas provocadas pela discriminação e marginalização, por motivos raciais, étnicos, religiosos, de gênero e outros" (Brasil, 1996).
} 
Prouni, privilegiando o processo de constituição de significados e de incorporação prática de princípios instituintes que concorrem para a construção e a objetivação do projeto de aquisição do diploma de curso superior. Destaco, nos itinerários sociais, as interações com agentes de mediação que ultrapassam o sistema de valores da família nuclear e das respectivas redes de relações.

Ao tomar como unidade de análise os itinerários sociais de estudantes, assumo, concomitantemente, a interpretação do contexto em que a questão do ingresso no Ensino Superior se coloca como problemática obrigatória; e as contribuições sociológicas que podem oferecer aqueles que tomaram seu itinerário como alavanca exemplar do combate às desigualdades socioeconômicas.

Ao me referir à mediação social, posiciono-me diante da proposta analítica que a concebe contrapondo-se "aos essencialismos e positivismos, aos substantivismos absolutizantes, bem como à dicotomização entre indivíduo e sociedade" (NEVES, 2008, p. 23). Trata-se de uma proposta que:

Alude à representação dialética porque valoriza as representações e as transformações do mundo, a institucionalização, a conciliação, a conformação e o questionamento quanto às regras que legitimam reconhecidas ordens sociais. Implicando, portanto, no reconhecimento dos significados coletivamente produzidos e intercomunicados, a utilidade explicativa do termo mediação funda-se na abertura para compreensão da construção da ordem social (NEVES, 2008, p. 24).

Diante de tal proposta, a mediação social é concebida como processo de intercomunicação entre diferenciados universos sociais, "só alcançáveis se corresponderem a saberes obtidos pelo mediado, isto é, se este se apresenta como sujeito de produção de inerentes novos saberes" (NEVES, 2008, p. 39). Isto significa que a ação do mediador não se restringe a interligar mundos diferenciados, pois ele também constrói e, portanto, tenta relativizar as representações dos mundos sociais que pretende interligar e o campo de relações que viabiliza esse modo específico de interligação.

Sob tal perspectiva, a mudança pensada pelo processo de mediação não significa a passagem de um universo de significados a outro. A ação dos mediadores sociais no processo de mudança para a posição de estudantes universitários não é concebida como sendo resultante da imposição da vontade dos primeiros. Isto seria destituir esses atores, os estudantes, de voz e vez. É preciso considerar a mediação construída na participação ativa tanto de mediadores quanto de mediados, pois é o entendimento 
da ação recíproca entre tais atores que conduz à compreensão do "conjunto das forças sociais em jogo, isto é, colocar o ator na história, para se interrogar sobre a produção das situações históricas" (NEVES, 2008, p. 39). Do ponto de vista metodológico, busquei me aproximar da perspectiva proposta por Bertaux (1997), optando pela realização de entrevistas do tipo "relato de vida". Considerando que o termo "história de vida" apresenta-se de forma pouco conveniente, uma vez que não distingue a história vivida por uma pessoa e o relato feito por ela, Bertaux (1997) elege por opção epistemológica, da qual compartilho, "relatos de vida" como unidade de análise. Assim o faz compreendendo que o termo se apresenta de forma epistemologicamente mais adequada, uma vez que um relato pessoal somente corresponde a uma aproximação da história objetivamente ou subjetivamente vivida por alguém. Portanto, ao optar pela reconstituição da história de vida de alguém, exclusivamente através do seu próprio relato, o pesquisador somente tem a ilusão de tê-lo feito. De acordo com o mencionado autor, "o relato de vida resulta de uma forma particular de entrevista, uma entrevista narrativa, ao curso da qual um pesquisador solicita a uma pessoa, denominada sujeito, a contar toda ou parte de sua experiência vivida" (BERTAUX, 1997, p. 06). Defini como "categoria de situação" estudantes, beneficiários do Prouni, residentes em bairros do município de Cariacica/ES que, entre o primeiro semestre do ano de 2005 e o segundo do ano de 2008, ingressaram em Instituição de Ensino Superior privada, situada em Vitória, capital do Estado do Espírito Santo. Realizei entrevistas com vinte estudantes, moradores do município de Cariacica, matriculados nos cursos com os quais tive maior contato, na condição de docente: Serviço Social, Psicologia, Nutrição, Educação Física, Filosofia e Administração. A escolha dos estudantes desses cursos também ocorreu por representarem duas situações distintas: nos cursos de Psicologia, Nutrição e Educação Física observa-se maior distinção de atributos sociais entre estudantes bolsistas e não bolsistas. Nos demais, tal distinção é pequena. Um grande número de estudantes não-bolsistas caracteriza-se por atributos sociais bastante semelhantes aos bolsistas. Foram selecionados os estudantes residentes no município de Cariacica, pois, por diferentes experiências, conquistei facilidades para a inserção no local enquanto pesquisadora e também para interpretações dos dados coletados ${ }^{3}$. Privilegiei para o trabalho de campo, como loci de referência, não somente o universo institucional da faculdade, mas, também, o espaço de moradia e de sociabilidade dos estudantes em pauta. Parte das observações e entrevistas foram realizadas em algumas moradias ou em espaços sociais, em bairros onde residem os entrevistados, posto que percebi a importância de observar não somente a inserção dos estudantes no universo institucional, onde ocupam a posição de alunos-bolsistas, como, também, no universo onde residem e compartilham experiências com familiares, amigos e vizinhos, a partir das quais exaltam a singularidade de ser um dos poucos a ingressar no curso superior.

Além de ter morado na região durante 23 anos e de ter exercido a profissão de professora de História em escolas localizadas em Cariacica, havia realizado, na ocasião, três pesquisas de campo em bairros do município. 
Este artigo se encontra organizado da seguinte forma: nas duas seções seguintes procedo à análise dos itinerários sociais dos estudantes aqui considerados, destacando o processo de interação com diferentes agentes de mediação social como fundamental à construção e à objetivação do projeto de ingresso no Ensino Superior. Na quarta seção, procuro demonstrar que, em grande parte dos itinerários analisados, cultiva-se a crença de que curso da vida deve se referenciar pela necessidade de crescer, constituindo-se em espécie de princípio orientador da vida. Na seção seguinte, discuto os dilemas da mobilidade social vivenciados pelos alunos bolsistas do Prouni, a partir da inserção no universo da faculdade. Por fim, na sexta seção, apresento as conclusões.

\section{Itinerários sociais e mediações subjacentes}

O projeto de ingressar na faculdade e obter um diploma de curso superior é construído ao longo dos itinerários sociais dos estudantes. Todavia, a possibilidade de deslocamento para uma nova posição social só se torna possível, na maioria dos casos, a partir da constituição de redes de apoio e da interação com agentes que operam como mediadores, por estarem situados para além do universo da família nuclear. Operacionaliza-se, portanto, pela ação orientada segundo fins almejados, mas incertos, isto é, como projeto desnaturalizado, não evidentemente definido pelas famílias dos estudantes.

Ao analisar casos de "sucesso escolar" nas classes populares, destacando as causas do improvável, e contrapondo-se às análises que buscam explicações deterministas para situações heterogêneas, Lahire (2004) propôs uma perspectiva analítica centrada na concepção de interdependência dos fenômenos, mais particularmente no conceito de configuração social, conforme definição de Elias (1994). O autor procurou demonstrar o quanto as singularidades existentes nas configurações familiares são fundamentais para a interpretação desse processo.

Nessa mesma perspectiva, muitos outros pesquisadores fundamentaram seus trabalhos. No Brasil, especialmente no campo da sociologia da educação, um bom número de estudos foi produzido procurando demonstrar a importância das configurações familiares para os casos de "longevidade escolar" (VIANA, 2005) nas classes populares. Concebo como inegável a importância da ação dos agentes mediadores presentes nas famílias, especialmente no processo de socialização primária, como edificantes de um projeto de escolarização bem-sucedido. No entanto, especialmente nas consideradas sociedades complexas, no processo que Berger e Luckmann (2001) chamaram de "socialização secundária", outras redes são tecidas e outras mediações constituídas. 
O processo de mudança para a posição de estudantes universitários pressupõe a interação com diferenciados mediadores, posicionados, na maior parte das vezes, em quadros institucionais que ultrapassam os limites das redes de relações da família nuclear. Tal interlocução se dá tanto na elaboração do projeto como em sua execução. Os referidos agentes podem ser mediadores "personalizados", como membros da família extensa, professores, colegas de trabalho, mas também e muitas vezes, mediadores do tipo "formal-legal". Esses últimos, posicionados nas organizações e programas governamentais, como é o caso dos técnicos que atuam no Prouni, ou afiliados a projetos e programas não governamentais, como aqueles que atuam em cursos do tipo Pré-vestibular para Negros e Carentes (PVNC) organizados pelos movimentos sociais, expressões de um projeto coletivo de ampliar o ingresso na universidade pelas classes populares.

Outros trabalhos também demonstraram, mesmo de forma indireta, as relações que estudantes de classes populares estabelecem com mediadores personalizados ou com aqueles do tipo formal-legal no processo de mudança para a posição de estudantes universitários. Refiro-me aos estudos desenvolvidos por Dauster (2004), Silva (2003), Teixeira (2003) e Honorato (2004). A primeira autora analisou a entrada e permanência de estudantes beneficiados por uma bolsa social (institucional) de uma universidade não pública. Honorato (2004), assumindo como propósito discutir as "estratégias coletivas em torno da formação universitária", analisou os itinerários de estudantes que ingressaram na Universidade Federal do Rio de Janeiro (RJ), a partir da inserção nos cursos PVNC. Silva (2003) buscou analisar itinerários escolares bem-sucedidos, objetivados por moradores das comunidades da Maré - um dos maiores complexos de favelas do Rio de Janeiro - rumo ao curso superior. Por sua vez, Teixeira (2003) teve a intenção de contribuir para o estudo das relações raciais, através da análise dos itinerários de estudantes e professores negros de uma IES pública, a Universidade Federal Fluminense. Constatando que o perfil dos seus entrevistados se caracteriza por "indivíduos de origem social mais baixa, que frequentaram escolas de primeiro e segundo graus de ensino deficiente e que, por alguma razão, conseguem ascender ao ensino superior, considerado de bom nível" (TEIXEIRA, 2003, p. 186), a autora demonstra que a capacidade de estabelecer uma rede de solidariedade e ajuda foi o fator determinante das trajetórias em ascensão.

Embora não tomando os agentes e redes de mediação como perspectiva de análise, posto que adotam objetivos diferentes dos aqui propostos, esses estudos corroboram o argumento por mim desenvolvido, à medida que consideraram, como fundamentais, na construção e consolidação do projeto de ingresso no Ensino Superior, as relações que os mencionados estudantes estabeleceram para além do universo familiar. 


\section{Universos de mediação social e acesso ao ensino superior}

Mesmo que não definam até quando estudar e, na grande maioria das vezes, a possibilidade da obtenção de um título universitário não seja vislumbrada, os agentes da família cultivam claramente uma ética da escolarização, segundo a qual aos estudos deve ser dispensado o máximo de atenção, tornando-o possível, ainda que sob condições pouco favoráveis. Compartilham a concepção de que a educação formal constitui-se no maior bem que os pais podem proporcionar aos filhos. Portanto, os gastos com os estudos devem se sobrepor aos demais bens de consumo. Em muitos casos, os pais destacam o quanto se sacrificaram para manter os filhos estudando. A este respeito, o relato de Marcos, aluno do curso de psicologia, parece bastante significativo.

Que eu me lembro meu pai sempre motivou a gente a estudar, nunca disse até quando estudar, se até o segundo grau, eu não me lembro bem ele falando disso, mas sempre falava para estudar. Se precisasse comprar livro, o pouco que ele ganhava ele comprava caderno, o que precisasse.

O projeto de escolarização se constitui, na maior parte das vezes, em empreendimento familiar. Tanto o incentivo do pai quanto o da mãe são também orientados por um desejo de que os filhos possam realizar um projeto que, eles próprios, embora desejassem, não conseguiram realizar, diante das condições vivenciadas. A escolarização dos filhos constitui-se, assim, numa espécie de "tentar outra vez", retomar, em outras condições, um desejo frustrado.

Como anteriormente destacado, o projeto de ingressar no curso superior constituise e objetiva-se, muito especialmente, a partir das interações que se estabelecem com indivíduos ou grupos que operam como mediadores sociais, posicionados nas diferentes redes de sociabilidade constituídas ao longo dos itinerários em questão.

Parte-se da concepção de que o conhecimento do outro deve ser valorizado em toda sua dimensão, uma vez que os agentes institucionais são portadores de posições e conhecimentos privilegiados. Em alguns casos, alguns desses agentes posicionam-se na própria rede de relações familiares, embora não necessariamente na família nuclear. São primos, tios ou maridos os principais incentivadores e/ou intermediários do projeto, como relata Lúcia, aluna do curso de Psicologia.

Fui crescendo, vendo toda empolgação deles. Quando vinham de férias para Vitória, traziam muitos materiais de apresentação de 
trabalhos, seminários, teatro e coisa e tal. Era tudo muito diferente. Lembro-me que minha prima falava da educação de uma forma empolgante e que ao mesmo tempo eu não entendia direito do que ela estava falando. Hoje quando me lembro do discurso dela, já consigo entender do que estava dizendo naquela época. E dessa forma fui acompanhando a graduação deles.

Não desprezando o apoio pregresso dos agentes familiares que incentivaram e apoiam essa projeção, como o pai ou irmãos mais velhos, é para além dos limites do mundo doméstico que se posicionam os agentes mediadores fundamentais ao projeto de mudança da posição social. São interações constituídas no mundo da escola, do trabalho, mas, também, nas instituições religiosas e no engajamento maior ou menor e da abertura para acesso a recursos diversos que os desdobramentos dos movimentos sociais populares propiciam. Estes últimos são instituições mediadoras dotadas de um projeto coletivo de mudança.

Em muitos dos itinerários analisados, após conclusão do hoje denominado Ensino Médio, muitos estudantes ingressam no mundo do trabalho. Em alguns casos, quando o fazem, adiam o projeto de ingresso na faculdade. Em outros, é a partir das interações com mediadores posicionados nesse universo que irão constituí-lo, percebendo o curso superior como importante e necessário. Em muitos casos, essa mediação é feita por colegas de trabalho que exercem funções especializadas e que possuem formação em nível de terceiro grau. Em geral, percebendo a dedicação e o bom desempenho no trabalho por parte dos estudantes, os estimulam a também buscarem uma especialização, apresentando-lhes um outro universo assim factível de projeção de novas posições no futuro. Nesta posição, o diploma de curso superior é percebido como necessário à mobilidade interna em um sistema de funções conhecido.

O exemplo de Raquel, aluna do último período do curso de Nutrição, é bastante significativo dessa abertura de mundo social. Começou a trabalhar na área da Saúde, num programa de combate à hipertensão, numa policlínica administrada pela Prefeitura Municipal de Cariacica. Com a conclusão do curso técnico em Enfermagem, condição básica para exercer o cargo de Coordenadora de Unidade, realizou processo seletivo interno, sendo aprovada. Percebendo-se em carreira ascendente, com o novo cargo e com o incentivo de médicos com os quais trabalhava, decidiu-se pelo ingresso no curso superior. Quando questionada a respeito das expectativas após conclusão do curso, respondeu:

Como eu já trabalho na Prefeitura de Cariacica, eu vou tentar encontrar alguma coisa relacionada à Nutrição. Porque nas escolas 
municipais tem nutricionista e eu vou correr atrás desta parte. E pra mim é mais fácil porque eu trabalho com muitos médicos que atuam em muitos lugares. Inclusive tem um médico que já me falou: eu vou conseguir alguma coisa na área de Nutrição para você. Eu achei interessante e vou correr atrás.

Em muitos casos, as interações com os agentes portadores de conhecimento quanto à interseção de universos se estabelecem a partir da ocupação de novas posições em movimentos sociais, mormente movimentos ambientais, religiosos, como é o caso dos grupos de jovens católicos e, com maior frequência, os movimentos com o propósito de ampliar o acesso ao Ensino Superior por parte das classes populares, como é o caso do PVNC. Seis dos entrevistados prepararam-se para o vestibular através desses cursos.

As interações com agentes mediadores integrados a movimentos sociais são amplas na correspondência dos fatores que incidem na emergência dessas ações coletivas, propiciando mais amplas alternativas de vislumbrar projetos de ingresso no curso superior. No caso de Wilson, aluno do curso de Filosofia, por exemplo, as relações construídas no movimento ambiental o colocaram em contato com um universo social diferente daquele com o qual convivia no seu dia-a-dia, abrindo caminhos para o projeto de ingressar na faculdade.

Tem uma associação de Cariacica e Viana chamada Asiarfa (Associação Intermunicipal Ambiental em Defesa do Rio Formate e seus Afluentes) que eu comecei a participar também. Em 2005, eu fui para Brasília, no II Encontro da Juventude pelo Meio Ambiente. Participei desse encontro por conta desse engajamento políticoambiental. Também porque meu pai foi militante político, sempre foi PT, ele me levava para as reuniões e eu acho que acabei sofrendo influência disso, né? Aí você conhece coisas novas e você percebe que os vizinhos e os amigos que não estão na faculdade, por exemplo, parece que o mundo deles é pequeno. Então, você vê um monte de coisas novas e quer trazer pra casa e as pessoas não aceitam e te olham com indiferença.

No caso de Pedro, aluno do curso de Serviço Social, as relações se entreteceram a partir do grupo de jovens da Igreja Católica.

Eu sempre fiz parte da Igreja Católica e era integrante do grupo de jovens, me lembro que eu e meus colegas sempre trocávamos 
informações sobre o que queríamos fazer no segundo grau, ensino médio e depois. Muitos falavam que iam estudar somente o segundo grau, uns diziam que iam fazer curso técnico, tanto que fui incentivado por um colega do grupo da igreja a tentar a prova do Cefetes, na época. Enfim, trocávamos informações sobre curso superior que faríamos depois do curso técnico.

Em dois outros casos, a participação em movimentos sociais, ainda que com objetivos diferentes dos PVNC e o contato com agentes que se colocaram como mediadores posicionados para além do grupo familiar foram representativos da abertura para outros universos, isto é, percepções e autorizações sociais para construção da expectativa de projeção de uma vida melhor, por onde seria possível crescer.

\section{Crescimento pessoal, valor moral e mobilidade}

Nos itinerários analisados, é frequente a concepção de que o curso da vida deve se referenciar pela necessidade de crescer. Embora se constitua numa espécie de princípio orientador da vida, o projeto de crescer é muito comumente concebido de maneira abstrata, muito pouco objetivado. Significativa parte dos relatos parece revelar, porém, que crescer adquire o significado de mudança da posição de subordinação, não objetivando, necessariamente, um grande aumento do capital econômico. A esse respeito, Marcos, aluno do curso de Psicologia, relatou o seguinte:

Na Telemar eu era ligador, lá a gente se autointitulava auxiliar técnico de telecomunicações, mas o título mesmo da função é ligador. A gente trabalhava dentro da central telefônica atendendo às demandas do instalador-reparador que ficava na rua. Era interessante também. Lá eu me identifiquei, o trabalho era interessante, mas não tinha muito para você crescer, o máximo que você podia fazer no trabalho era eu saber o máximo que eu pudesse sobre todo o sistema.

Embora pouco objetivado, muito comumente cultiva-se a crença de que o crescimento possa ser alcançado mediante a integração a curso superior, como se pode observar no relato seguinte de uma aluna do curso de serviço social.

Na época eu não sei se queria fazer administração ou psicologia. Eu não sabia ao certo não. Eu sabia que queria fazer um curso superior, eu queria crescer. 
Observa-se que, mesmo que não se saiba qual curso fazer, o importante é ter um diploma universitário. Por conseguinte, o curso superior apresenta-se como condição fundamental para a concretização do projeto de crescer, conforme demonstra, por exemplo, o relato de Larissa, concludente do curso de Serviço Social.

Trabalhei em comércio. Foram vinte anos de comércio. Eu crescia profissionalmente, mas crescia assim: de caixa passava pra analista de crédito, porque quem não tem o ensino superior não tem muita chance de crescer profissionalmente. Ai foi isso que me motivava também. Eu pensava: não posso ficar toda vida trabalhando no comércio, eu queria crescer.

O curso superior parece representar a autorização necessária para o estudante se apresentar como alguém dotado de conhecimentos específicos capazes de tornar possível a mudança da posição de trabalhador subordinado para a de trabalhador especializado e com mais autonomia. Observa-se, nos relatos, que o exercício de funções não especializadas, ligadas ao comércio, como de vendedor (a) ou caixa, parece se constituir numa das melhores expressões desta subordinação. Mais facilmente alcançável com o Ensino Médio e demonstrando a relatividade do valor atribuído ao trabalhador dotado apenas desse nível de ensino, o acesso inicial a essas funções representa mais claramente a posição de onde é preciso sair para ser possível crescer.

Uma vez constituído nas relações estabelecidas com os referenciados mediadores, a consolidação do projeto de ingresso no curso superior esbarra, num primeiro momento, em duas principais condições: a não aprovação nos exames vestibulares, impossibilitando o ingresso em uma universidade pública, e a ausência de condições materiais para pagar a mensalidade em uma IES privada. Diante dessas impossibilidades, a bolsa do Prouni é comemorada pelos estudantes como uma grande conquista, como o recurso que faltava para o ingresso no Ensino Superior.

Porém, se a conquista da bolsa possibilita o ingresso no curso superior, em pouco tempo percebe-se que não se trata de tarefa simples o cumprimento das exigências necessárias à sua manutenção. Enquanto preparam-se para o Exame Nacional do Ensino Médio, os estudantes também buscam reunir condições que, somadas à bolsa, permitam-lhes, de fato, estudar. Na maioria dos casos, especialmente por parte daqueles já inseridos no mercado de trabalho, buscam-se construir estratégias para conciliar trabalho e estudo. Entre os que não trabalham, a busca se dirige à construção de estratégias que lhes possibilitem possuir algum tipo de ganho financeiro necessário às demais despesas, desde passagens de ônibus até cópias dos textos para estudo. 
Nessas circunstâncias, os valores associados à ética do sacrifício orientam o processo de mobilidade e o dignificam. Só parece ser possível o deslocamento de posição social a partir da valorização de um sistema que exige não só dedicação, mas a abstinência relativa a determinadas práticas concebidas, como propiciadoras de prazer e bem-estar. É preciso dormir pouco, estudar nos fins de semana, não sendo praticamente possível reservar tempo para o lazer.

Embora tenham analisado o sacrifício com base no estudo minucioso e bem documentado de duas religiões, o Hinduísmo e o Judaísmo, Mauss e Hubert (2005), ao concluírem o "ensaio sobre a natureza e a função do sacrifício", chamaram a atenção para a importância da dimensão não propriamente religiosa de tal fato social. Argumentam que:

Pudemos ver, ao longo do estudo, quantas crenças e práticas sociais que não são propriamente religiosas se encontram em relação com o sacrifício. Tratamos sucessivamente da questão do contrato, da redenção, do castigo, da dádiva, da abnegação, das ideias relativas à alma e à imortalidade que são ainda a base da moral comum. Isso comprova a importância da noção de sacrifício para a sociologia (MAUSS; HUBERT, 2005).

Nesse sentido, as práticas representativas de uma ética do sacrifício, por parte dos estudantes, aproximam-se da proposta dos referidos autores ao relacionarem sacrifício e dádiva e explicitarem que:

[...] Em todo sacrifício há um ato de abnegação, pois quem se sacrifica se priva e se dá. Essa abnegação lhe é mesmo frequentemente imposta como um dever. [...] Mas essa abnegação e essa submissão não deixam de ter um lado egoísta. Se o que sacrifica dá alguma coisa de si, ele não se dá; ele se reserva prudentemente. É que se ele dá, é em parte para receber. O sacrifício se apresenta, então, sob um duplo aspecto. E um ato útil e uma obrigação. $O$ desinteresse se mescla ao interesse. Por isso ele foi frequentemente concebido sob a forma de um contrato (MAUSS; HUBERT, 2005).

No caso em questão, a conciliação entre o caráter obrigatório e utilitário do sacrifício parece clara. É necessário e obrigatório abnegar-se e privar-se para ser recompensado, pois, da mesma forma que é dando que se recebe, é também se sacrificando que se é recompensado. Postula-se a crença numa obrigatória recompensa diante do ato de dar-se em sacrifício, nos termos da moral da dádiva pautada nas obrigações de dar-receber e retribuir. Se me dou em sacrifico, receberei 
obrigatoriamente uma recompensa. Fazer um curso superior, deslocando-se para uma posição social supostamente de maior prestígio, constitui-se, para estes estudantes, a grande recompensa.

\section{Os dilemas da mobilidade social}

O processo de mobilidade é construído entre muitos dilemas e constrangimentos. A inserção em um novo universo de significados traz à tona sentimentos e sentidos diversos reveladores, muitas vezes, do dilema inerente à condição de ser universitário e bolsista. Mesmo que o outro não seja objetivamente definido, há, por parte da maioria dos estudantes, a sensação de que a vida transita entre dois mundos, em universos simbólicos diferentes. Por isso, ao mesmo tempo em que o acesso à nova posição é comemorado, a percepção da alteridade pode se apresentar como um desafio.

Apesar de, na maior parte das vezes, os estudantes tenderem, por efeitos de posição, a secundarizar as dificuldades no estabelecimento de relações com o abstratamente chamado "outro", parte deles revelou sentimentos de autoexclusão e de discriminação, evidenciando a dificuldade de convívio com as diferenças, neste caso, também expressa na desigualdade social.

Dauster (2004), ao analisar as relações entre estudantes integrantes do sistema de categorias denominadas por seus entrevistados de "bolsistas" e "elite", no universo de uma IES não pública da Zona Sul do Rio de Janeiro, o faz a partir das reflexões de Elias e Scotson (2000) a respeito dos estabelecidos e os outsiders. Estas categorias, de caráter relacional, são discutidas pelos mencionados autores em uma etnografia das relações de poder na comunidade de Winston Parva (nome fictício), próxima de Leicester, Inglaterra, localidade demarcada pela existência de um grupo de moradores antigos da "aldeia", os estabelecidos, que se colocavam como pessoas de "valor humano mais elevado" que o dos moradores do "loteamento" construído em época mais recente, os outsiders, estigmatizados pelos primeiros.

Mesmo considerando não ser produtivo radicalizar a analogia que propõe, Dauster procura demonstrar que os integrantes das categorias "bolsistas" e "elites" convivem em relações de interdependência tensa e desigual, que tanto separam quanto unem, tais quais os estabelecidos e os outsiders. Segundo a autora, "as distinções entre as duas categorias são percebidas em função de relações de evitação e exclusão, em processos de estigmatização e rotulação" (DAUSTER, 2004, p. 3). Observa ainda que: 
Nas queixas dos integrantes dos setores populares em relação a colegas de outros segmentos economicamente privilegiados, percebese que a chegada de seus membros à universidade particular é sentida como ameaça ao estilo de vida da universidade e à sua "qualidade", embora o que se entende por qualidade não esteja definido em nenhum momento (DAUSTER, 2004, p. 4).

As análises de Elias e Scotson (2000) apontam ser graças a um maior potencial de coesão que os antigos residentes de Winston Parva, os "estabelecidos", conseguiram reservar para as pessoas de seu tipo os cargos importantes das organizações locais, como o conselho, a escola ou o clube, e deles excluir firmemente os moradores de outras áreas, aos quais, como grupo, faltava coesão. As exclusão e a estigmatização dos outsiders pelo grupo estabelecido constituíam-se em armas poderosas para que este último preservasse sua identidade e afirmasse sua superioridade, mantendo os outros firmemente em seu lugar.

No caso que analiso, não se faz adequado se referir a um grupo já estabelecido na faculdade quando da chegada dos estudantes bolsistas. Também não se observa nenhum grande potencial de coesão e montagem de estratégias visando à ocupação de cargos que confiram poder, por parte de um grupo de possíveis estabelecidos. Desde o início de suas atividades acadêmicas, a faculdade conta com a presença em seu corpo discente de alunos beneficiários de um programa institucional de bolsas. Também é grande a presença, sobretudo em alguns cursos, de alunos que, embora não bolsistas, são oriundos de famílias de baixa renda. De fato, não é possível se referir a não bolsistas ou a bolsistas como grupo, pelo menos no sentido sociológico atribuído ao termo.

A existência de percepções e atitudes discriminatórias confirma práticas mais isoladas, não se constituindo em uma estratégia de um grupo coeso, caracterizado por sentimento de pertencimento e formulador de estratégias de controle social e manutenção de poder.

Portanto, se os que discriminam compartilham da percepção de fazerem parte de algum grupo de "valor humano mais elevado", tal percepção parece assentada em relações sociais estabelecidas para além dos muros da faculdade, amparadas em um sistema social que se estrutura de forma hierárquica e excludente.

Diante do inicial sentimento de discriminação e autoexclusão, os estudantes bolsistas, aos poucos, vão construindo percepções orientadoras de estratégias de diferenciação. Imbuídos da crença de prevalecer no quadro institucional um 
sistema meritocrático, pautado no alcance de resultados acadêmicos satisfatórios, esforçam-se para torná-los evidentes, conquistando a almejada posição de reconhecimento e aceitação por parte do outro.

Se a inserção num outro universo, o da faculdade, apresenta-se como um desafio, também o é continuar pertencendo ao universo social de origem. Ao mesmo tempo em que se autopercebem e são percebidos, por familiares e amigos, como indivíduos detentores de qualidades especiais, acabam, muitas vezes, assumindo posição que desqualifica o universo social de origem como um mundo pequeno, do qual não parece mais interessante participar.

Por essa via, a posição de viver no limiar entre dois universos sociais distintos pode representar, ao mesmo tempo, satisfação pelos desafios superados, como também, certo sentimento de solidão decorrente de uma ruptura com o universo familiar ou dos amigos. O sentido do pertencimento passa a constituir-se por muitas tensões e constrangimentos. Nesses termos, o processo de mobilidade assume significados expressivos dos prazeres da conquista, mas também tradutores de dores e sofrimentos.

\section{Conclusão}

A condição de estudante bolsista imprime desafios às interrelações na nova posição, e também traz à tona dificuldades de outra ordem. Torna-se muito evidente que a bolsa, por si só, não garante as necessidades intrínsecas à permanência e conclusão do curso superior, pois, além de ser preciso satisfazer aos critérios de competência exigidos para a sua manutenção, é também necessário dispor de tempo e de outro tipo de recurso para financiar os demais gastos com a faculdade.

Os valores que orientam a ética do sacrifício se fazem presentes, em muitos casos, dentro de um quadro de alternativas referenciadoras de uma situação de risco. Para alguns entrevistados aliar trabalho e estudo representava o risco de perder a bolsa, uma vez que precisavam garantir rendimento satisfatório para sua manutenção. Em outros casos, a alternativa é deixar o emprego, impondo-se o sacrifício de abster-se de determinados consumos, não mais possíveis sem o salário mensal. A posição inicial de estudante-trabalhador é transformada, durante o curso, para a de apenas estudante. Isto quando percebem a impossibilidade de obter resultados satisfatórios na faculdade, tendo que também trabalhar. Em um dos casos a alternativa foi negociar uma demissão, de um emprego considerado como uma grande conquista, podendo contar com os recursos do Fundo de Garantia por Tempo de Serviço. 
Essas condições vão configurando um campo de possibilidades representativas da importância do diploma do curso superior para os estudantes. Não é fácil obtê-lo, mas tal obtenção é tão importante que deve se sobrepor a qualquer outra exigência.

Diante de tais condições e, dotados da autopercepção de que estão construindo trajetória ascendente, cultivam a crença de que superar as dificuldades e permanecer estudando dependem da capacidade individual de se colocar em sacrifício.

Por essa via, não somente o ingresso, mas também a permanência na faculdade não são concebidos como processos que devam resultar da mobilização coletiva mais ampla, como uma bandeira política a ser empenhada. Constrói-se a crença na possibilidade da permanência e da conclusão do curso superior como uma vitória pessoal, com a certeza de que os compromissos pautados nas relações de dar, receber e retribuir, tradutores da moral da dádiva (MAUSS, 1974), estão sendo cumpridos.

Percebendo-se em ascensão social e cultivando o princípio segundo o qual o percurso da vida deve se referenciar pela permanente necessidade de crescer, ou seja, pela expansão de si, pela autorização própria a se expressarem em público, e pela minimização dos constrangimentos em diversos planos (a certos recursos materiais de serviços, por exemplo), os estudantes concebem o curso superior como a grande possibilidade de mudança no plano individual. Desse deslocamento social, alguns se atribuem uma posição de liderança no sentido de propiciar aos familiares e vizinhos as mesmas oportunidades conquistadas ou facilitadas por outrem. Essa atribuição nem sempre corresponde ao desejo social dos demais, razão pela qual muitos deles passam a se sentir estranhos no seu ambiente. Enfim, crescer (tout court) ou crescer na vida sinalizam uma abertura para o mundo, destacando a abertura em si, sem, necessariamente, um ponto de chegada pré-definido. Mais precisamente, expressam a virtude que cria o passaporte necessário à conquista de uma posição de maior prestígio social, adquirindo, no sentido mais restrito, o significado de uma vitória pessoal. E, por isso mesmo, a distinção social que só é de fato reconhecida se apontar para as possibilidades e os quereres dos outros, isto é: crescer é necessário e possível.

Imbuídos dessa crença, e por um processo de reprodução agonística do crescimento, os entrevistados manifestam um forte desejo de realizar um curso de pós-graduação. Na maioria, eles se referem a um curso de especialização lato sensu, mas também manifestam o desejo de cursar Mestrado e Doutorado. Adquirir o grau de pós-graduado parece se constituir em importante estratégia para consolidação do passaporte adquirido com o curso superior. 
Nesses termos, obter o diploma de Ensino Superior, realizar uma pós-graduação e inserir-se no mercado de trabalho de forma melhor qualificada e socialmente valorizada colocam-se como formas objetivas do desejo de crescer, princípio orientador da vida. Embora de início pouco objetivado, ele é melhor avaliado a posteriori, configurando de certa maneira um ethos coletivo ou familiar, demonstrado em diversos casos em que esse desejo reafirma e mapeia significados de mudança de posição de subordinação e alcance de maior prestígio e status social.

Conforme definiu Bourdieu (1998), “os grupos de status impõem aos que neles desejam participar, além de modelos de comportamentos, modelos da modalidade dos comportamentos, ou seja, regras convencionais que definem a maneira justa de executar os modelos" (p. 16). Esses grupos, portanto, se distinguem não pela maneira de ter bens, mas de usar esses bens.

Em uma sociedade como a brasileira, tão operada por princípios de hierarquização e exclusão, o título universitário, bem como os seus mencionados desdobramentos, especialmente a grande possibilidade de pertencimento a um grupo de status em que se acredita seja possível ter voz e vez, é delinear ou vislumbrar expectativas de se igualar àqueles que se posicionam nos concebidos patamares mais elevados dessa hierarquia. 


\title{
Itineraries of schooling and underlying mediations: the experience of prouni's beneficiaries
}

\begin{abstract}
In this article I analyze the social itineraries of students coming from families considered as part of popular classes, who benefit from Prouni. I discuss the process of constitution of meanings and of practical incorporation of principles which contributed to the constitution and feasibility of the acquisition of an academic title. This acquisition is conceived in a non-naturalized way, possible as a result of an interaction with mediators placed in institutional frameworks that go beyond the limits of the nuclear family. The formal-legal mediation structure of the Prouni agents is presented as fundamental. However, the process of retention and graduation is marked by many dilemmas, translated into both forms to relate with alterity and with financial issues. Getting a university degree represents the possibility to gain a better pay and valued profession and to be included in a group with higher prestige and social status.
\end{abstract}

Keywords: Prouni. University degree. Social mediation.

\section{Itinerarios de escolarización y mediaciones subyacentes: la experiencia de los beneficiarios del prouni}

\section{Resumen}

En este articulo se analizan los itinerarios sociales de estudiantes de familias consideradas de clases populares, y beneficiarios del Prouni. Se discute el proceso de constitución del significado y la incorporación práctica de principios que han contribuido a la construcción y objetivación de la adquisición de un título académico. Este proyecto se construye de manera no naturalizada, efectuándose por la interacción con agentes mediadores, colocados en marcos institucionales que van más allá de los límites de la familia nuclear. La mediación formal-legal de los agentes del Prouni se presenta como fundamental. Sin embargo, el proceso de retención y graduación está marcado por muchos dilemas, tanto en las formas de relación con la alteridad, como en las de orden financiero. Concluir la educación superior representa la posibilidad de ejercer una profesión mejor remunerada y valorada, además de ser parte de un grupo de mayor prestigio y estatus social.

Palabras clave: Prouni. Titulación universitaria. Mediación social. 


\section{Referências}

ALMEIDA, S. C. O avanço da privatização na educação brasileira: o Prouni como uma nova estratégia para a transferência de recursos públicos para o setor privado. 2006. 123 f. Dissertação (mestrado em educação) - Programa de Pós-Graduação em Educação, Universidade Federal Fluminense, Niterói, 2006.

BERGER, P. L.; LUCKMANN, T. A construção social da realidade: tratado de sociologia do conhecimento. 22. ed. Petrópolis: Vozes, 2001.

BERTAUX, D. Les récits de vie: perspectives ethnosociologiques. Paris: Nathan, 1997.

BOURDIEU, P. A economia das trocas simbólicas. São Paulo: Perspectiva, 1998.

BRASIL. Ministério das Relações Exteriores e Ministério da Justiça. Décimo relatório periódico relativo à Convenção Internacional sobre a Eliminação de Todas as Formas de Discriminação Racial. Brasília, DF: 1996.

CARVALHO, C. H. A. O ProuniI no Governo Lula e o jogo político em torno do acesso ao ensino superior. Educação e Sociedade, v. 27, n. 96, p. 979 -1000, out. 2006. doi:10.1590/S0101-73302006000300016

DAUSTER, T. Uma revolução silenciosa: notas sobre o ingresso de setores de baixa renda na universidade. In: A questão social no novo milênio: Congresso Luso-Afro-Brasileiro de Ciências Sociais, 2004, Coimbra. Disponível em $<$ www.ces.uc.pt/lab2004/pdfs/TaniaDauster.pdf > . Acesso em: 30 mar. 2014.

ELIAS, N. O processo civilizador. Rio de Janeiro: Jorge Zahar, 1994. 2 v.

ELIAS, N.; SCOTSON, J. L. Os estabelecidos e os outsiders: sociologia das relações de poder a partir de uma pequena comunidade. Rio de Janeiro: Jorge Zahar, 2000.

HERINGER, R.; FERREIRA, R. Análise das principais políticas de inclusão de estudantes negros no ensino superior no Brasil no período 2001-2008. In: PAULA, M.; HERINGER, R. (Org.). Caminhos convergentes: estado e sociedade na superação das desigualdades raciais no Brasil. Rio de Janeiro: Heinrich Böll Stiftung, 2009. p. 137-96.

HONORATO, G. S. Estratégias coletivas em torno da formação universitária: Status, igualdade e mobilidade entre desfavorecidos. 2004. 185 f. Dissertação (mestrado em sociologia) - Universidade Federal do Rio de Janeiro, Instituto de Filosofia e Ciências Sociais, Rio de Janeiro, 2005. 
LAHIRE, B. Sucesso escolar nos meios populares: as razões do improvável. São Paulo: Ática, 2004. (Fundamentos, 136).

MAUSS, M. Ensaio sobre a dádiva: formas e razão da troca nas sociedades arcaicas. In: MAUSS, M.; LÉVI-STRAUSS, C. Sociologia e antropologia. São Paulo: EDUSP, 1974. V. 2, p. 183-314.

MAUSS, M.; HUBERT, H. Sobre o sacrifício. São Paulo: Cosac Naify, 2005.

NEVES, D. P. (Org.). Mediação social e mediadores políticos. In:

Desenvolvimento social e mediadores políticos. Porto Alegre: editora da UFRGS, 2008. p. 21-44.

SILVA, J. S. Por que uns e não outros? caminhada de jovens pobres para a universidade. Rio de Janeiro: Sete Letras; 2003.

SOUZA, S. R. O pré-vestibular para negros como instrumento de política compensatória: o caso do Rio de Janeiro. In: Oliveira, I. (Org.). Relações raciais e educação: novos desafios. Rio de Janeiro: DP\&A Editora; 2003. (Coleção Políticas da cor).

TEIXEIRA, M. P. Negros na universidade: identidade e trajetórias de ascensão social no Rio de Janeiro. Rio de Janeiro: Pallas, 2003.

VIANA, M. J. B. As práticas socializadoras familiares como lócus de constituição de disposições facilitadoras de longevidade escolar em meios populares. Educação e Sociedade, v. 26, n. 90, p. 107-25, jan./abr. 2005. doi:10.1590-S0101-73302005000100005

\section{Informações da autora}

Andrea Bayerl Mongim: Doutora em Antropologia pela Universidade Federal Fluminense - UFF. Pós-doutoranda em Ciências Sociais pela Universidade Federal do Espírito Santo - UFES. Contato: ambayerl@hotmail.com 